\title{
The role of penectomy in penile cancer-evolving paradigms
}

\author{
Sarah O’Neill, Mitchell Barns, Filip Vujovic, Mikhail Lozinskiy
}

Department of Urology, Royal Perth Hospital, Perth, Australia

Contributions: (I) Conception and design: S O’Neill, M Lozinskiy; (II) Administrative support: S O’Neill, M Lozinskiy; (III) Provision of study materials or patients: None; (IV) Collection and assembly of data: S O’Neill, M Barns, F Vujovic; (V) Data analysis and interpretation: All authors; (VI) Manuscript writing: All authors; (VII) Final approval of manuscript: All authors.

Correspondence to: Mikhail Lozinskiy. Department of Urology, Royal Perth Hospital, Perth, Australia. Email: mlozinsky@gmail.com.

\begin{abstract}
Penile cancer is a rare cancer, with the majority treated with penile preserving methods. There remains a role for partial and totally penectomy for advanced and more proximal penile cancers. Significant functional and psychological morbidity can ensue for patients undergoing surgical management. Recent studies and guidelines are changing the way Urologists approach surgical management of penile malignancies. Reductions in safe surgical margin recommendations from $2 \mathrm{~cm}$ to $3-5 \mathrm{~mm}$ provide surgeons with the ability to perform penile preserving techniques to maximise patient functionality. These guidelines are reflected by recent studies showing that smaller surgical margins; although heralding higher rates of local recurrence, have no detriment on cancer specific or overall survival rate. Although oncological clearance remains the primary outcome for surgical management of penile cancer, the ability to perform radical salvage surgery at a later date means patients are more likely to experience a longer period of functionality without sacrificing oncologic outcomes. The importance of patient education on regular self-examination as well as clinic follow up are key in identifying local recurrence and planning salvage surgery if needed to maintain oncologic control. Ongoing studies into the functional and psychological outcomes of patients undergoing partial penectomy show encouraging results however further studies are needed to elucidate long-term outcomes. The evolving paradigm of surgical management in penile malignancy is shifting to favour organ preserving techniques in order to maximise functional, psychological and aesthetic outcomes without compromising patients' oncologic outcomes-however a role still exists for radical surgery in advanced penile malignancy.
\end{abstract}

Keywords: Partial penectomy; radical penectomy; total penectomy; penile cancer

Submitted Apr 05, 2019. Accepted for publication Aug 02, 2019.

doi: 10.21037/tau.2019.08.14

View this article at: http://dx.doi.org/10.21037/tau.2019.08.14

Penile cancer is a rare cancer, and the majority can be treated with penile preserving methods. There is however still a role for partial and total penectomy in both advanced and more proximal penile cancers. Historically, a $2-\mathrm{cm}$ surgical margin was thought to be required to achieve adequate oncological control, leading to patients undergoing disfiguring surgery in the form of partial or radical penectomy (1). More recently however, there has been a shift in the treatment paradigm with evidence demonstrating that a margin of $5 \mathrm{~mm}$ provides appropriate oncological control. This has been reflected in the European Association of Urology (EAU) Guidelines with 3-5 mm margin as the general recommendation for safe margin length (1-3). Although higher rates of local recurrence have been shown to occur in this setting of smaller margins and organ preserving techniques; this has not been shown to effect cancer specific or overall survival $(1,4,5)$. Thus, the paradigm of organ sparing surgery has shifted to where possible favour penile preserving techniques to improve functional and cosmetic outcomes.

Prognosis of penile cancer varies dependent on histological subtype of the tumour $(1,6)$. Squamous cell carcinoma (SCC) comprises $48-65 \%$ of cases and its prognosis is dependent on location, stage and grade. Other 
subtypes with good prognosis include warty, verrucous and papillary carcinoma. Basaloid and sarcomatoid carcinomas infer very poor prognosis. Other histological subtypes comprise less than $1 \%$ of cases and are mostly poor prognosis. These histological subtypes also need to be considered in preoperative surgical planning.

Tumour location and local staging are imperative considerations for the choice of appropriate surgical treatment of penile cancer. Although $80 \%$ of primary penile cancer can be treated with organ sparing methods such as circumcision, laser ablation and wide local excision due to their distal locations (7); disease that extends into the urethra or corporal bodies, or disease that has failed more conservative management usually requires more invasive procedures such as partial or radical penectomy. The penile length and body habitus of the patient are also serious considerations in surgical planning. The treatment aim is for complete oncological clearance while preserving penile length and function where possible. Total or radical penectomy are typically reserved for high grade penile cancers or those in which a partial penectomy would leave a residual stump not suitable for micturition (1). Given the low incidence of penile cancer and the advancement of organ sparing surgical techniques, the rates of total penectomy have reduced in more recent times as surgeons aim for better cosmetic and functional outcomes without compromising disease-specific survival rates $(1,6)$.

\section{Partial penectomy}

Partial penectomy is indicated in penile cancer involving the shaft which cannot be treated minimally invasively. It involves resection proximal to the tumour and terminalisation of the urethra and corpora. Partial penectomy delivers low recurrence rates of less than $10 \%$ and allows for better preservation of penile function thereby remaining the standard of care for patients with disease contained to the penile shaft $(8,9)$. Although recent recommendations for resection margins are only $5-10 \mathrm{~mm}$ allowing better salvation of penile length, this should be considered in conjunction with tumour grade as determined on initial biopsy. Lower grade T1/T2 tumours have been shown to extend to less than $1 \mathrm{~cm}$ while higher grade 3 tumours can invade up to $1.5 \mathrm{~cm}$ deep (3). A penile stump of $2.5-3 \mathrm{~cm}$ is required to achieve essential functionality from the penis however this does not infer that patients are content psychologically with this outcome (10).

\section{Radical penectomy}

Radical penectomy is indicated in most $\mathrm{T} 3$ and all $\mathrm{T} 4$ staged penile tumours $(1,6)$, though it may also be required in $\mathrm{T} 2$ disease if a functional residual stump is not attainable. If a $5-\mathrm{mm}$ clear margin is possible with T3 tumours, a partial penectomy could also be considered, given the low recurrence rates associated with this procedure and the ability to perform radical salvage surgery (11). Invasion of the urethra is classified as stage pT2 or pT3-dependent on involvement of the corpora spongiosum or cavernosum respectively. The survival outcomes are dependent on invasion and corporal involvement rather than the location of tumour within the urethra (9). Involvement of the proximal urethra is more typical of highly aggressive SCC which is associated with poor patient outcomes (12).

Total penectomy involves excision of the penis up to or near the suspensory ligament, conserving the proximal corpora cavernosa (13). Radical penectomy, performed less commonly, involves the excision of the penis with removal of the entire corporeal body. Following excision of the penis, the urethra is brought out to the perineum to form a perineal urethrostomy to allow micturition while seated (13).

\section{Outcomes}

A paper by Lont et al. described the 5 -year disease recurrence rates in patients with either $\mathrm{T} 1 / \mathrm{T} 2$ disease who underwent a penis preserving technique $(\mathrm{n}=157)$ vs. a partial penectomy ( $\mathrm{n}=100)$ (14). In these populations the recurrence at 5 years was substantially lower in the partial penectomy group at $12 \%$ compared to $37 \%$ in the conservative management group. These results were supported by a more recent large retrospective study completed in 2008 in which the oncological outcomes in $\mathrm{pN} 0$ or $\mathrm{pN}+$ patients undergoing penile preserving techniques such as laser and wide local excision were compared to those undergoing either partial or total penectomy (5). Of the 415 patients who underwent penile preserving treatment $27.7 \%$ (117 patients) developed a local recurrence vs. 5.3\% (15 patients) who underwent partial/total penectomy. However, despite this relatively large increase in local recurrence, the 5-year survival rate remained at $92 \%$. This is likely confounded by the ability to perform more radical salvage surgery however. This number was considerably reduced in patients with regional spread $(32.7 \%)$ and in patients with distant metastasis where there were zero survivors at 22 months. This highlights the importance of early diagnosis as well 
as consistent post-operative follow up to prevent early recurrence leading to distant disease spread.

A more recent study by Veeratterapillay et al. described 65 patients who underwent penile preserving surgery for $\mathrm{T} 2$ or lower disease and showed a local recurrence rate of only $6 \%(15)$. In this cohort, $85 \%$ of patients were able to achieve and maintain an erection at 1 year, however psychosocial outcomes were not measured.

In all the above studies, partial penectomy consistently showed significantly lower rates of disease recurrence at all time points. This however had no impact on 5-year survival, as the ability to perform re-do radical surgery for localized disease usually remains. The benefits of these types of surgeries however include a lower likelihood of requiring re-do surgery (as shown by reduced recurrence rates) whereby patients are likely to retain a functional organ for a longer period before requiring more radical organ sacrificing surgery.

The functional outcomes and quality of life post total penectomy are difficult to accurately describe here given the relative paucity of data specific to it. Several studies have looked to assess function post-partial penectomy, however some small studies involving optional patient questionnaires have indicated that as expected there are significant effects on a patient's sex life and quality of life (16-18). This is in keeping with data from partial penectomy patient's, however it appears that there are not the same negative effects on partner relations or one's own assessment of masculinity with partial penectomy as compared to total penectomy (19). Despite the detrimental effects of total penectomy on well-being with increased rates of depression and sexual anxiety, suicide rates among patients with penile cancer are surprisingly the lowest out of all urological malignancies (20).

Several studies have reviewed sexual function after partial penectomy (21-23). Post-operative IIEF questionnaire scores were statistically worse for all domains of sexual function after partial penectomy (1). A study by Romero et al. (21) compared the sexual function and satisfaction before and after partial penectomy and showed that $55.6 \%$ of patients were able to sustain an erection substantial enough to allow sexual penetration, with $72.2 \%$ of these patients remaining able to ejaculate with sexual stimulation. However out of this cohort, only $33 \%$ of patients maintained their pre-operative sexual frequency, with the main reason for less frequent intercourse relating to embarrassment about shortened penis size and the absence of a glans penis (21).

\section{Conclusions}

With close follow up regimes and regular self-examination, penile preserving surgery offers preferable functional and cosmetic outcomes without having to compromise on oncological outcome. There remains, however, an important role for total penectomy and perineal urethrostomy in advanced local disease. Oncological clearance and outcomes remain the primary outcome for the surgical management of penile cancer. The future in penile cancer surgery looks to involve further investigation and ongoing review of the oncological outcomes and local recurrence rates with these decreased surgical margins as well as optimising the reconstruction following these invasive surgeries. The EAU guidelines are already considering basing the recommended negative surgical margin on the grade of the tumour however this has limitations based on the difficulties of penile cancer grading preoperatively (1).

\section{Acknowledgments}

Funding: None.

\section{Footnote}

Provenance and Peer Review: This article was commissioned by the Guest Editor (Shomik Sengupta) for the series "Surgery for Urologic Cancers" published in Translational Andrology and Urology. The article has undergone external peer review.

Conflicts of Interest: The series "Surgery for Urologic Cancers" was commissioned by the editorial office without any funding or sponsorship. The authors have no conflicts of interest to declare.

Ethical Statement: The authors are accountable for all aspects of the work in ensuring that questions related to the accuracy or integrity of any part of the work are appropriately investigated and resolved.

Open Access Statement: This is an Open Access article distributed in accordance with the Creative Commons Attribution-NonCommercial-NoDerivs 4.0 International License (CC BY-NC-ND 4.0), which permits the noncommercial replication and distribution of the article with the strict proviso that no changes or edits are made and the original work is properly cited (including links to both the formal publication through the relevant DOI and the license). 
See: https://creativecommons.org/licenses/by-nc-nd/4.0/.

\section{References}

1. Hakenberg OW, Compérat EM, Minhas S, et al. EAU guidelines on penile cancer: 2014 update. Eur Urol 2015;67:142-50.

2. Minhas S, Kayes O, Hegarty P, et al. What surgical resection margins are required to achieve oncological control in men with primary penile cancer? BJU Int 2005;96:1040-3.

3. Agrawal A, Pai D, Ananthakrishnan N, et al. The histological extent of the local spread of carcinoma of the penis and its therapeutic implications. BJU Int 2000;85:299-301.

4. Lindegaard JC, Nielsen OS, Lundbeck FA, et al. A retrospective analysis of 82 cases of cancer of the penis. $\mathrm{Br}$ J Urol 1996;77:883-90.

5. Leijte JA, Kirrander P, Antonini N, et al. Recurrence patterns of squamous cell carcinoma of the penis: recommendations for follow-up based on a two-centre analysis of 700 patients. Eur Urol 2008;54:161-8.

6. Van Poppel H, Watkin NA, Osanto S, et al. Penile cancer: ESMO Clinical Practice Guidelines for diagnosis, treatment and follow-up. Ann Oncol 2013;24 Suppl 6:vi115-24.

7. Palminteri E, Berdondini E, Lazzeri M, et al. Resurfacing and reconstruction of the glans penis. Eur Urol 2007;52:893-8.

8. Korets R, Koppie TM, Snyder ME, et al. Partial penectomy for patients with squamous cell carcinoma of the penis: the Memorial Sloan-Kettering experience. Ann Surg Oncol 2007;14:3614-9.

9. Velazquez EF, Soskin A, Bock A, et al. Positive resection margins in partial penectomies: sites of involvement and proposal of local routes of spread of penile squamous cell carcinoma. Am J Surg Pathol 2004;28:384-9.

10. Pow-Sang MR, Benavente V, Pow-Sang JE, et al. Cancer of the penis. Cancer Control 2002;9:305-14.

11. Philippou P, Shabbir M, Malone P, et al. Conservative surgery for squamous cell carcinoma of the penis: resection margins and long-term oncological control. J Urol

Cite this article as: O’Neill S, Barns M, Vujovic F, Lozinskiy M. The role of penectomy in penile cancer-evolving paradigms. Transl Androl Urol 2020;9(6):3191-3194. doi: 10.21037/ tau.2019.08.14
2012;188:803-8.

12. Leijte JA, Gallee M, Antonini N, et al. Evaluation of current TNM classification of penile carcinoma. J Urol 2008;180:933-8; discussion 938.

13. Loughlin KR. Surgical management of penile carcinoma: the primary lesion. BJU Int 2006;97:655-67.

14. Lont AP, Gallee MP, Meinhardt W, et al. Penis conserving treatment for T1 and T2 penile carcinoma: clinical implications of a local recurrence. J Urol 2006;176:575-80; discussion 580.

15. Veeratterapillay R, Sahadevan K, Aluru P, et al. Organpreserving surgery for penile cancer: description of techniques and surgical outcomes. BJU Int 2012;110:1792-5.

16. Kieffer JM, Djajadiningrat RS, van Muilekom EA, et al. Quality of life for patients treated for penile cancer. J Urol 2014;192:1105-10.

17. Sosnowski R, Wolski JK, Kulpa M, et al. Assessment of quality of life in patients surgically treated for penile cancer: Impact of aggressiveness in surgery. Eur J Oncol Nurs 2017;31:1-5.

18. Park EJ, Stroie F, Psutka SP et al. Sexual and Voiding Outcomes in Post-Penectomy Penile Cancer Patients. JOJ Uro \& Nephron 2018. doi: 10.19080/ JOJUN.2018.06.555678.

19. Sosnowski R, Kulpa M, Kosowicz M, et al. Quality of life in penile carcinoma patients - post-total penectomy. Cent European J Urol 2016;69:204-11.

20. Simpson WG, Klaassen Z, Jen RP, et al. Analysis of Suicide Risk in Patients with Penile Cancer and Review of the Literature. Clin Genitourin Cancer 2018;16:e257-61.

21. Romero FR, Romero KR, Mattos MA, et al. Sexual function after partial penectomy for penile cancer. Urology 2005;66:1292-5.

22. D'Ancona CA, Botega NJ, De Moraes C, et al. Quality of life after partial penectomy for penile carcinoma. Urology 1997;50:593-6.

23. Alei G, Letizia P, Sorvillo V, et al. Lichen sclerosus in patients with squamous cell carcinoma. Our experience with partial penectomy and reconstruction with ventral fenestrated flap. Ann Ital Chir 2012;83:363-7. 